IF Sér. Reg. n. 54 p. 5-23 maio 2016

http://dx.doi.org/10.4322/ifsr.2016.001

ISSN on-line 2179-2372

\title{
EDUCAÇÃO AMBIENTAL NA ESTAÇÃO ECOLÓGICA DE AVARÉ, ESTADO DE SÃO PAULO, BRASIL ${ }^{1}$
}

\section{ENVIRONMENTAL EDUCATION IN AVARÉ ECOLOGICAL STATION, SÃO PAULO STATE, BRAZIL}

\author{
Sueli HERCULIANI ${ }^{2,3}$; Marilda Rapp de ESTON²; Waldir Joel de ANDRADE; \\ Paulo Henrique dos SANTOS $^{2}$; Fernando DESCIO ${ }^{2}$, Rosângela Célia Ribeiro de OLIVEIRA ${ }^{2}$
}

RESUMO - A Estação Ecológica de Avaré - E.Ec. Avaré é uma Unidade de Conservação de Proteção Integral, com 719,02 hectares, localizada no município de Avaré, Estado de São Paulo, gerenciada pelo Instituto Florestal. Os objetivos deste trabalho foram identificar a potencialidade da Estação Ecológica de Avaré com relação ao meio natural, às estruturas físicas e recursos humanos existentes, necessários para a implantação do Subprograma de Educação Ambiental. Para a obtenção dos dados primários, foram realizadas entrevistas semiestruturadas, aplicadas junto ao responsável pela Estação Ecológica de Avaré e à Secretária Municipal de Educação de Avaré. Foram também realizadas visitas técnicas para análise da infraestrutura existente e da potencialidade para desenvolver atividades de educação ambiental na área. Para a obtenção dos dados secundários, foi realizada uma revisão dos materiais bibliográficos. São fornecidas propostas para o Subprograma de Educação Ambiental, já que a pesquisa revelou que a E.Ec. Avaré não dispõe de infraestrutura física para o desenvolvimento de atividades de educação ambiental, carece de trilhas interpretativas e, desde sua criação, não tem um Subprograma de Educação Ambiental, faltando, inclusive, recursos humanos para o desenvolvimento desta atividade.

Palavras-chave: Unidade de Conservação; conscientização; meio ambiente.

\begin{abstract}
Avaré Ecological Station is an Integral Protection Conservation Unit of 719.02 hectares, located in the municipality of Avaré, São Paulo state, managed by the Forestry Institute. The objectives of this study were to identify the potential of Avare Ecological Station in relation to the natural environment, the physical structures and human resources required for the implementation of environmental education subprogram. Semi-structured interviews were conducted to obtain the primary data, these interviews were applied to the responsible for the Avaré Ecological Station and to the Avaré Municipal Secretary of Education. We also carried out technical visits to analyze the existing infrastructure and the capability to develop environmental education activities in the area. To obtain the secondary data a review of library material was performed. Proposals are provided for the Environmental Education Subprogram. The survey revealed that this Ecological Station has no physical infrastructure for the development of environmental education activities, it needs interpretive trails and it has not a Subprogram of Environmental Education since its creation, and the it lacks human resources for the development of this activity.
\end{abstract}

Keywords: Conservation Unit; awareness; environment.

\footnotetext{
${ }^{1}$ Artigo científico. Recebido para análise em 20.08.2015. Aceito para publicação em 22.03.2016. Publicado on-line em 15.06.2016. ${ }^{2}$ Instituto Florestal, Rua do Horto, 931, 02377-000, São Paulo, SP, Brasil.

${ }^{3}$ Autor para correspondência: Sueli Herculiani - sueliherculiani@iflorestal.sp.gov.br
} 


\section{INTRODUÇÃO}

$\mathrm{O}$ século XX foi marcado por uma série de fatores que representaram, historicamente, um marco na evolução social e econômica em escala mundial. A exemplo disto, podemos citar que a partir da Revolução Industrial e técnico-científica, surge então um novo modelo de civilização que se impôs, trazendo a industrialização com sua forma de produção e organização de trabalho. Contudo, esse processo também desencadeou uma série de desajustes ambientais e sociais da modernidade.

À medida que tal modelo de desenvolvimento provocou efeitos negativos mais graves, surgiram manifestações e movimentos que refletiam a consciência de parcelas da população sobre os problemas que a humanidade poderia enfrentar caso continuasse afetando tão intensamente o meio ambiente.

Em 1863, Thomas Huxley escrevia em "Evidências sobre o lugar do homem na natureza" a relação interdependente entre os seres vivos e o meio ambiente, ou seja, essa preocupação em torno dos problemas ambientais há tempos já vem ocupando a mente de filósofos, cientistas, artistas e religiosos que reconheciam a importância da natureza e tinham interesse em protegê-la (Huxley, 2013).

Porém, foi somente no século XIX que surgiram as primeiras iniciativas na criação de áreas legalmente protegidas para resguardar os ecossistemas e as paisagens naturais. $\mathrm{O}$ marco histórico desse tipo de iniciativa é o Parque Nacional de Yellowstone, criado em 1872, nos Estados Unidos. No Brasil, somente no ano de 1937 foi criada a primeira Unidade de Conservação - o Parque Nacional de Itatiaia, no Rio de Janeiro. Sua criação teve como base o Código Florestal de 1934. A iniciativa de criação de parques nacionais difundiu-se por vários países, diversificando-se com o passar do tempo, passando a receber a denominação genérica de Unidade de Conservação - UC.

É neste sentido que os conceitos de Educação Ambiental, isto é, um conjunto de temáticas relativas não só à proteção de vida no planeta, mas também à melhoria da qualidade de vida das comunidades, compõe a lista dos temas de relevância internacional, dentro de Unidades de Conservação e em demais âmbitos.

Formaliza-se, em 1972, com a Conferência das Nações Unidas sobre o Meio Ambiente, ou Declaração de Estocolmo, a preocupação de grande parte dos países com as questões relacionadas ao meio ambiente (Declaração..., 1972).

Em resposta às recomendações da Conferência de Estocolmo, a Organização das Nações Unidas para Educação, Ciência e Cultura - UNESCO promoveu, em 1975, em Belgrado (Iugoslávia), o Encontro Internacional em Educação Ambiental, no qual criou o Programa Internacional de Educação Ambiental - PIEA (Encontro..., 1975). Nessa Conferência, foram orientados os princípios de que a educação ambiental deve ser continuada, multidisciplinar, integrada às diferenças regionais e voltada aos interesses nacionais.

Outro marco importante foi a realização em 1977, da Conferência Intergovernamental de Educação Ambiental na cidade de Tbilisi (ex-URSS). Também organizado pela UNESCO, o encontro foi um ponto culminante da primeira fase do Programa Internacional de Educação Ambiental. Considerou-se que a Educação Ambiental deve ser orientada para solucionar os problemas através da participação ativa dos atores da educação, entre outros públicos. Deve-se empregar o foco interdisciplinar, aproveitando-se o conteúdo específico em cada disciplina, devendo-se construir um processo contínuo e permanente, iniciando-se na educação infantil e continuando através de todas as fases do ensino formal e não formal (Conferência..., 1977).

Em 1988, a Constituição da República Federativa do Brasil (CF/88) dedicou o Capítulo VI ao Meio Ambiente e no Art. 225, Inciso VI, determina que cabe ao "[...] Poder Público, promover a Educação Ambiental em todos os níveis de ensino [...]" (Brasil, 1988).

Em junho de 1992, no Rio de Janeiro, a Organização das Nações Unidas - ONU organizou uma Conferência sobre Meio Ambiente e Desenvolvimento, conhecida como RIO-92/ECO-92 (Conferência..., 1992). A Conferência resultou na elaboração de documentos de extrema importância para o desenvolvimento humano no tocante às questões ambientais, a Carta da Terra, documento baseado na afirmação de princípios éticos fundamentais (Carta da Terra, 2000), o Tratado da Educação Ambiental, que norteia ações voltadas à sustentabilidade e à proteção da vida na terra (Tratado da Educação Ambiental, 1992) e a Agenda 21, que tenta promover um novo padrão de desenvolvimento humano, que agrega, em escala planetária, justiça social, eficiência econômica e proteção ambiental (Agenda 21, 1992). 
HERCULIANI, S. et al. Educação ambiental na Estação Ecológica de Avaré.

A temática meio ambiente está inserida em diversos setores de responsabilidade social, nos quais temos a participação da sociedade, seja em âmbito da educação formal, seja de forma conduzida por Organizações Não Governamentais - ONGs, Organizações da Sociedade Civil de Interesse Público - OSCIPs, entre outras.

A Política Nacional de Educação Ambiental, Lei no 9795/99 (Brasil, 1999), dispõe que o Poder Público deve incentivar a participação de empresas públicas e privadas no desenvolvimento de programas de Educação Ambiental em parceria com escolas, universidades e organizações não governamentais. Também cabe ao Poder Público a sensibilização da sociedade para a importância das Unidades de Conservação que, no caso, contam com o apoio de educadores ambientais, responsáveis por despertar a sensibilização e consciência ambiental nos visitantes, bem como nas comunidades do entorno das Unidades de Conservação, além de serem considerados peças-chave para a concretização dos princípios que envolvem a educação ambiental, propiciando a sustentabilidade local.

A criação do Sistema Nacional de Unidades de Conservação - SNUC, através da Lei $n^{\circ} 9.985$, de 18 de julho de 2000 (Brasil, 2000), contribuiu sobremaneira para o aprimoramento do exercício da gestão das áreas protegidas, regulamentando o que diz respeito à participação social no processo de criação das unidades, ao justo tratamento das populações tradicionais, à regularização fundiária, à garantia da gestão financeira das Unidades de Conservação e, entre os seus principais objetivos, destacam-se a contribuição para a manutenção da diversidade biológica, a proteção das espécies ameaçadas de extinção e a contribuição para a preservação e restauração da diversidade de ecossistemas naturais, além de promover a educação e interpretação ambiental, a recreação e o lazer.

Em 2006, é criado o Sistema Estadual de Florestas do Estado de São Paulo - SIEFLOR, através do Decreto $n^{\circ} 51.543$ (São Paulo, 2006), que estabeleceu como um dos objetivos do Programa de Uso Público despertar a consciência crítica para a importância da conservação nas Unidades de Conservação de Proteção Integral, bem como a participação ativa da sociedade, através do Subprograma de Educação Ambiental.

Duas medidas políticas importantes na área de educação ambiental, no que se refere ao Estado de São Paulo, foram também a Lei $n^{\circ} 12.780$ de 2007, que instituiu a Política Estadual de Educação Ambiental (São Paulo, 2007) e, em 2008, a regulamentação do Uso Público em Unidades de Conservação de Proteção Integral (São Paulo, 2008).

As Unidades de Conservação representam um importante recurso para sensibilizar e conscientizar as pessoas sobre a necessidade de proteger o meio ambiente. Fundamental para o sucesso do processo de transferência de conhecimentos é adequar o Programa de Educação Ambiental às diferentes percepções de cada grupo. Ao considerarmos a interpretação e representação dos distintos espaços percebidos, podemos influenciar o exercício da ética ecológica, no qual estabelecemos relação entre o meio ambiente e o homem e criamos exercícios de compromisso e responsabilidade em prol da proteção e tutela do meio ambiente, através da observação e interpretação da natureza. Na busca da inserção de valores fundamentados na conscientização, sensibilização e comprometimento responsável, insere-se a educação ambiental de caráter interpretativo e perceptivo, que transpassa os métodos tradicionais usados na transmissão de saberes e valores conservacionistas.

Dessa manrira, condutas proativas e mudanças de comportamento são estimuladas através da educação ambiental, a partir da apropriação de conhecimentos e da consciência crítica de que a sociedade é responsável pelos problemas ambientais.

Unidades de Conservação, como as Estações Ecológicas, são áreas representativas de ecossistemas brasileiros destinadas à realização de pesquisas básicas e aplicadas de Ecologia, à proteção do ambiente natural e ao desenvolvimento da educação conservacionista, de acordo com a Lei Federal $\mathrm{n}^{\circ}$ 6.902, de 27 de abril de 1991 (Brasil, 1991). Nesse contexto a Estação Ecológica de Avaré é uma área natural protegida, localizada no sudoeste do Estado de São Paulo, importante para a realização de atividades de educação ambiental. 
Essa Estação Ecológica tem sua origem fincada na Ferrovia Paulista S/A, sendo transferido o imóvel no ano de 1976, à Companhia Agrícola Imobiliária e Colonizadora vinculada à Secretaria de Estado da Agricultura - o Horto Florestal. No ano de 1981, é transferido de forma provisória à administração do Instituto Florestal de São Paulo, sendo esta transferência formalizada através do Decreto $\mathrm{n}^{\circ} 49.983$, de 6 de setembro de 2005 (Arzolla et al., 2012). Posteriormente, essa área foi categorizada como Estação Ecológica, Unidade de Conservação de Proteção Integral, através do Decreto $n^{\circ}$ 56.616/2010 (São Paulo, 2010).

Os objetivos deste trabalho foram identificar a potencialidade da E.Ec. Avaré com relação ao meio natural, às estruturas físicas e aos recursos humanos existentes, necessários para a implantação do Subprograma de Educação Ambiental.

\section{MATERIAL E MÉTODOS}

A Estação Ecológica de Avaré é uma unidade recoberta por formação vegetal típica de Cerrado, com abrangência de 719,02 hectares, situada no município de Avaré (Figura 1).

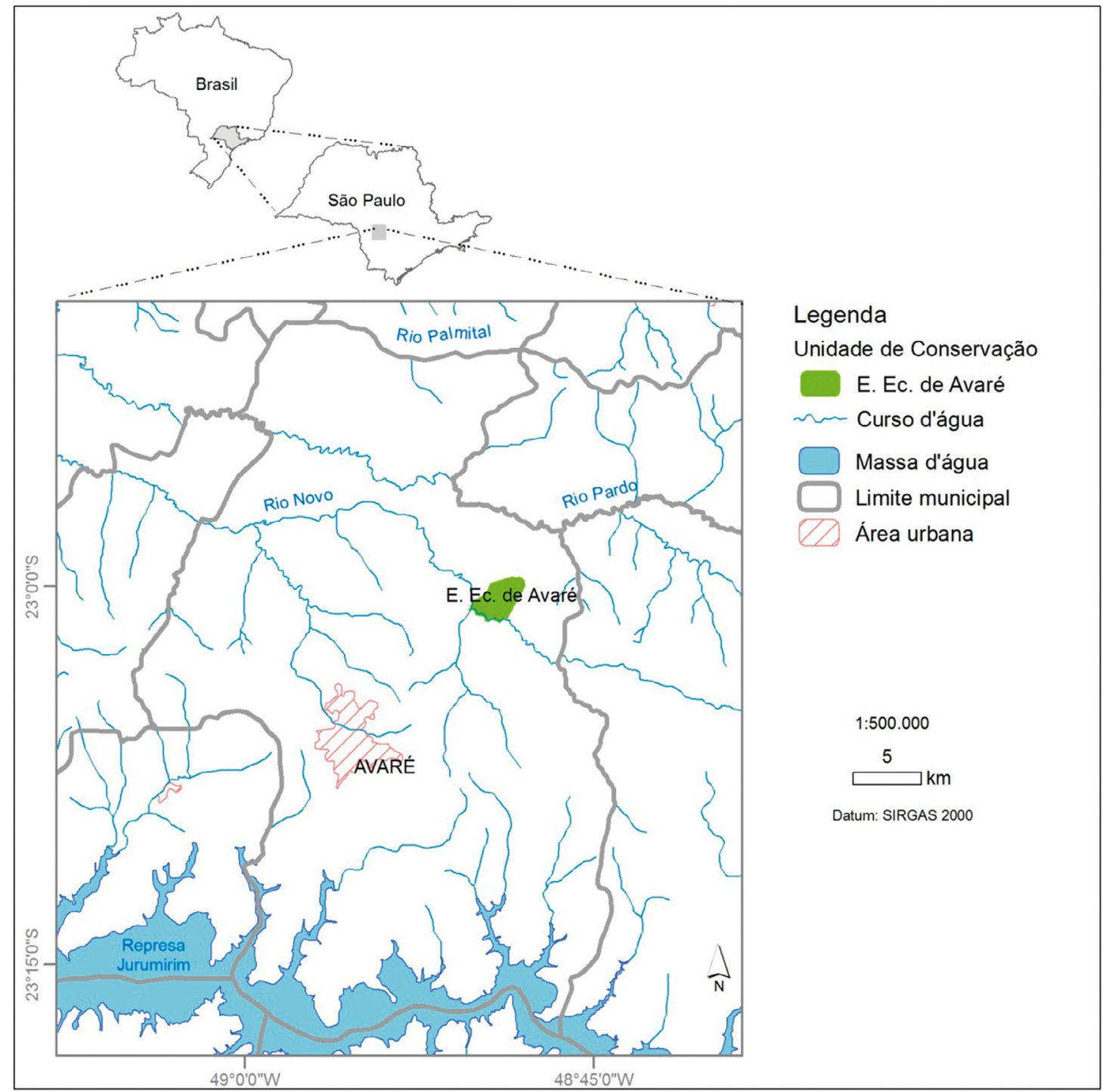

Figura 1. Localização da área de estudo

Figure 1. Location of study area. 
O clima da região é Cwa, mesotérmico com inverno seco e verão quente, segundo a classificação de Köppen, a temperatura média anual é de $20,3{ }^{\circ} \mathrm{C}$ e a precipitação anual é de $1.274 \mathrm{~mm}$ (Sentelhas et al., 1999). As altitudes variam de 700 a 803 metros e o tipo de solo na região é o Latossolo Vermelho (Oliveira et al., 1999).

Para a obtenção dos dados primários foram realizadas entrevistas semiestruturadas, utilizando-se do roteiro recomendado por Lüdke e André (1986) (Apêndice A), aplicadas junto ao responsável pela Estação Ecológica de Avaré e à Secretária Municipal de Educação de Avaré, com o objetivo de verificar os interesses e necessidades do município no tocante ao desenvolvimento de projetos e atividades junto à rede municipal de ensino. Foram também realizadas visitas técnicas para análise da infraestrutura existente e da potencialidade de desenvolver atividades de educação ambiental na área.

Para a obtenção dos dados secundários, foi realizada uma revisão dos materiais bibliográficos existentes sobre a área e da legislação pertinente.

\section{RESULTADOS E DISCUSSÃO}

A pesquisa revelou que a E.Ec. Avaré não dispõe de infraestrutura física para o desenvolvimento de atividades de educação ambiental, carece de trilhas interpretativas e que, desde sua criação, não tem um Subprograma de Educação Ambiental implantado, faltando, inclusive, recursos humanos para o desenvolvimento desta atividade.

Para a implantação e o desenvolvimento do Subprograma de Educação Ambiental é imprescindível a formação de um quadro de pessoal; assim, se faz necessário estabelecer um quadro de monitores/estagiários cursando os níveis médio e superior de ensino, devidamente capacitados e atualizados por meio de cursos de formação.

Para o desenvolvimento do Subprograma de Educação Ambiental, conforme diagnosticado em campo, também são necessárias estruturas básicas a serem implantadas como:

a) instalação de um Centro de Visitantes;

b) adequação e instalação de sanitários e bebedouros, que atendam às normas da Associação Brasileira de Normas Técnicas - ABNT, Norma Brasileira - NBR 9050 (Associação Brasileira de Normas Técnicas - ABNT, 2015);

c) instalação de um espaço multiuso para atividades diversas, por exemplo, lanche dos estudantes, dotado com a devida estrutura física de bancos e mesas;

d) dotação da área com todos os cuidados relacionados à segurança dos visitantes e funcionários,

bem como o ordenamento territorial das estruturas de moradia funcional, para que não haja conflitos com as atividades de educação ambiental;

e) confecção de material de divulgação tais como fôlderes e cartazes para cada público a ser atendido;

f) confecção de placas e painéis informativos e indicativos, além das já existentes no local;

g) implantação de trilhas interpretativas.

A Estação Ecológica de Avaré não possui um Centro de Visitantes. Poder-se-ia utilizar para tal finalidade uma construção antiga, em madeira, que já existe no local e é considerada um patrimônio histórico (Figura 2). Um Centro de Visitantes serve para recepcionar o visitante, e tem como objetivo desenvolver atividades interpretativas, educativas e culturais sobre os recursos e possíveis problemas ambientais da área e da região (Marcondes et al., 2008).

É necessário que o Subprograma de Educação Ambiental esteja integrado com os demais programas de manejo, como, por exemplo, o de gestão e o de proteção. Uma maior segurança para a implantação de atividades de educação ambiental se faz necessária, bem como o ordenamento territorial das estruturas de moradia funcional, para que não haja conflitos com as atividades de educação ambiental (figuras 3 e 4 ). 


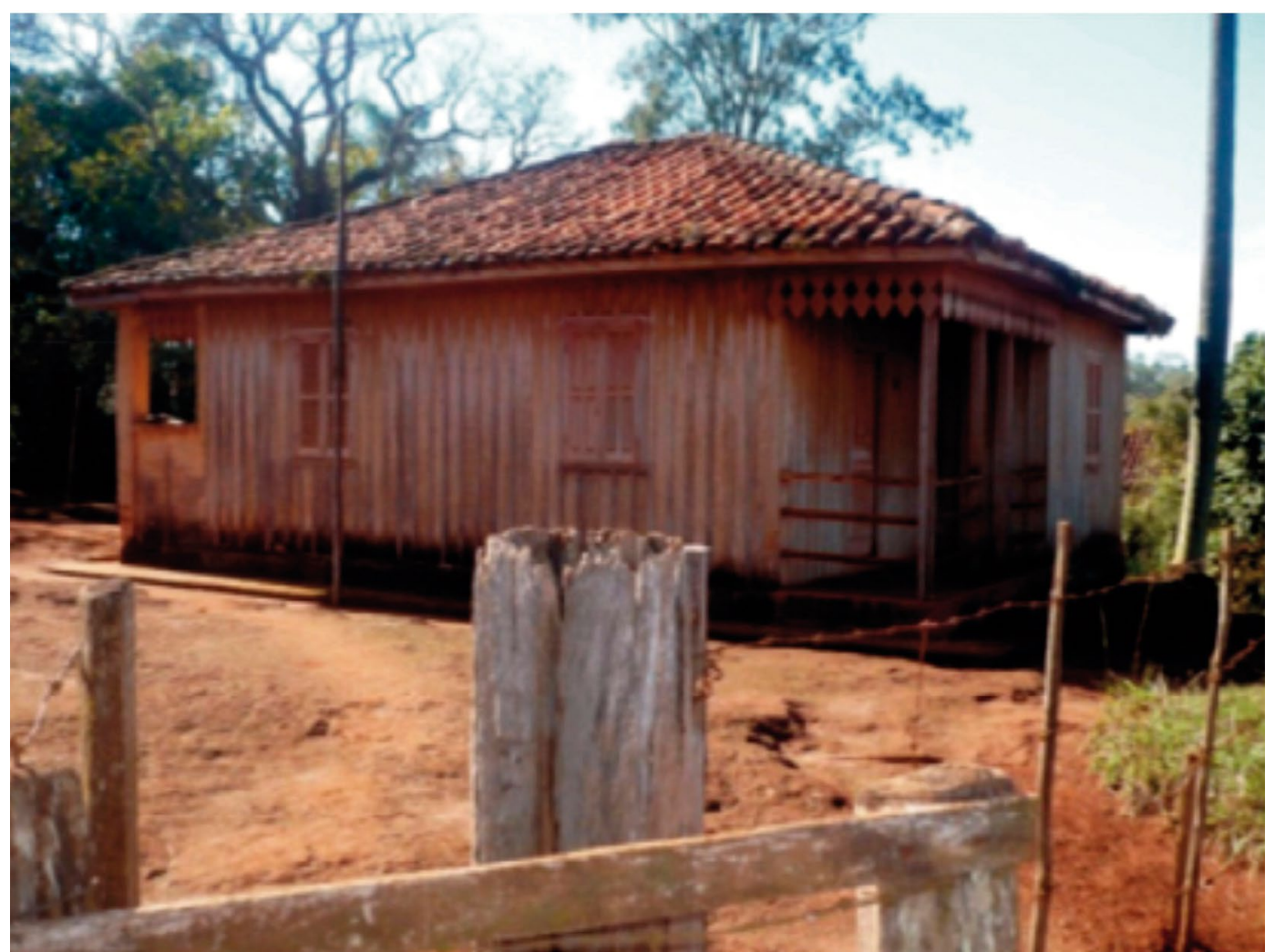

Figura 2. Patrimônio histórico com proposta de ser recuperado para ser utilizado como Centro de Visitantes. Figure 2. Historical heritage with proposal to be recovered for use as a Visitor Center.

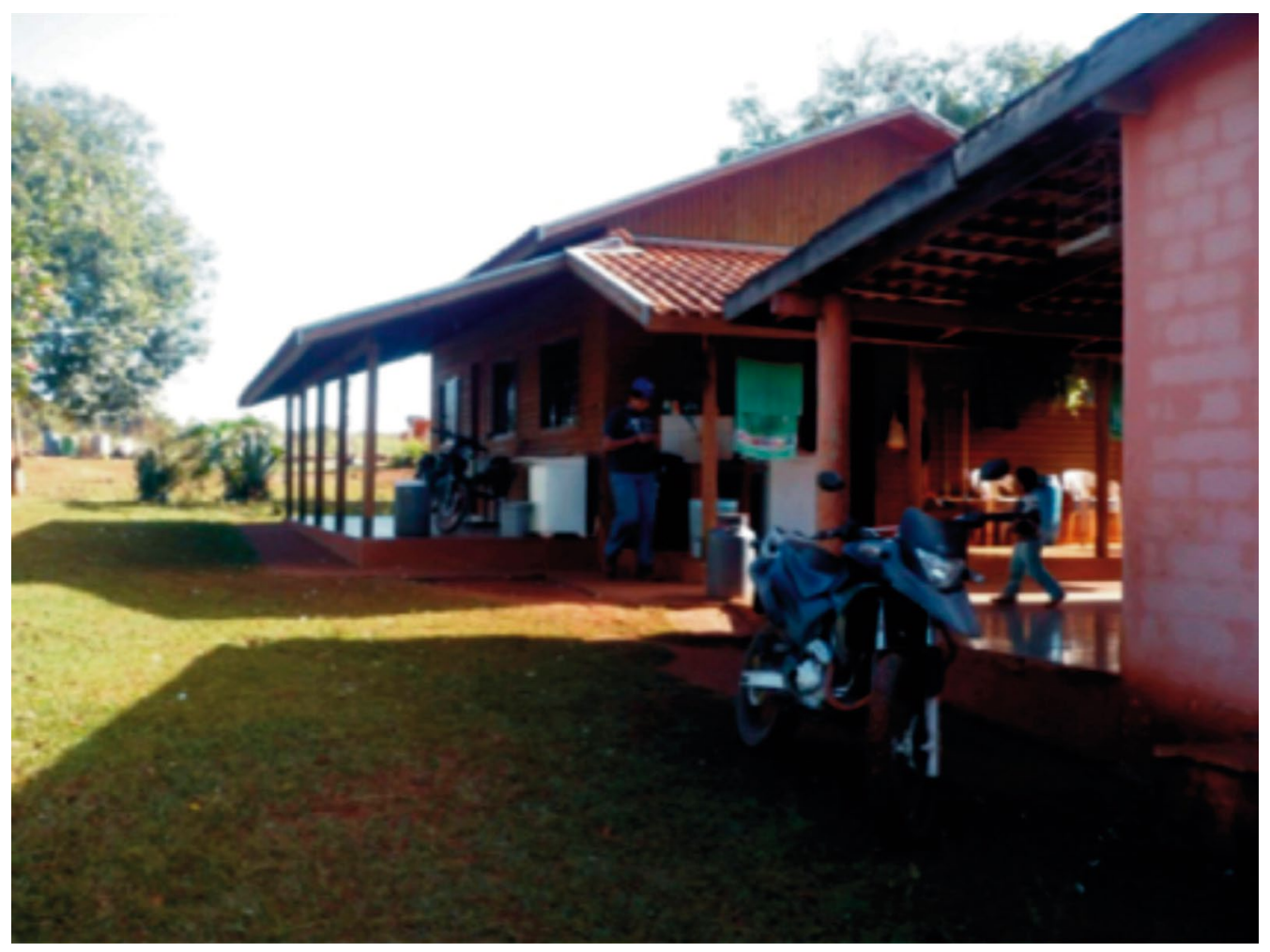

Figura 3. Moradia de funcionário.

Figure 3. Employee home. 


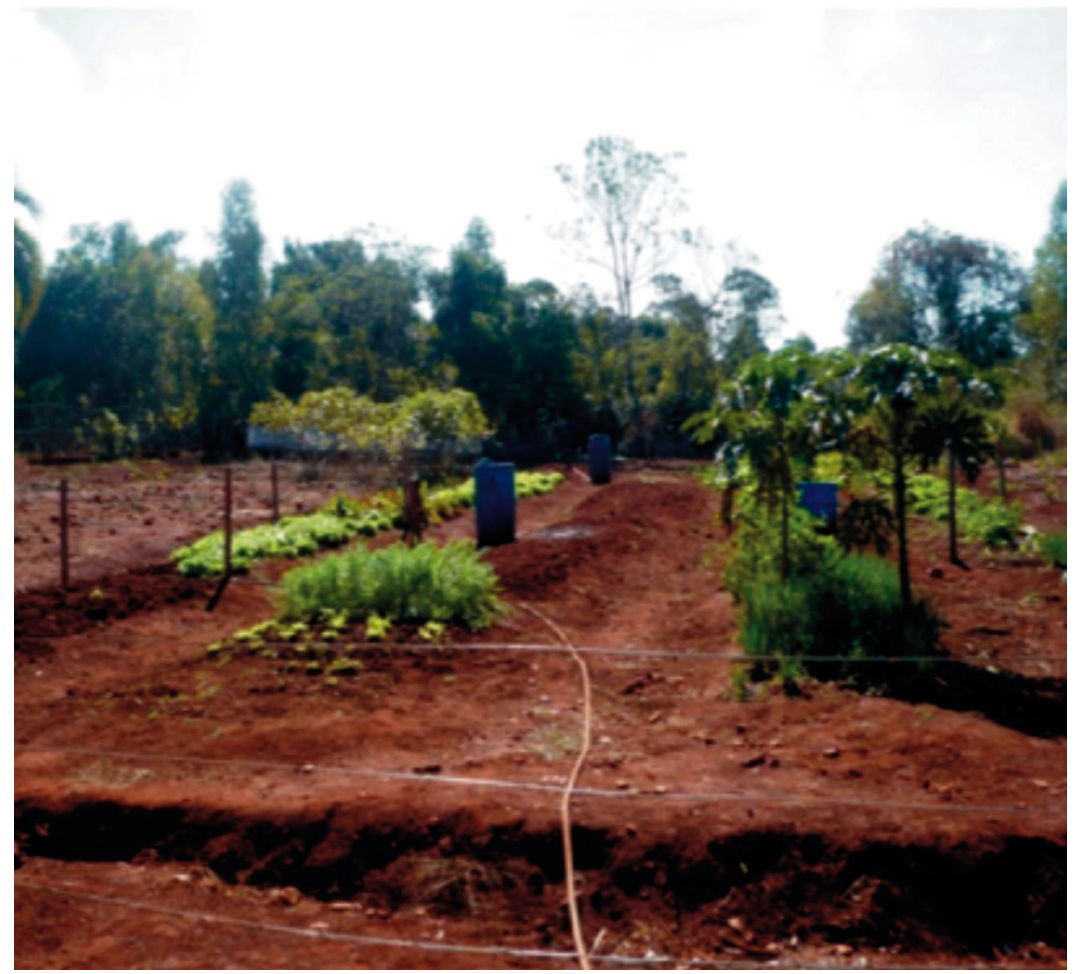

Figura 4. Horta de funcionário.

Figure 4. Employee garden.

Em relação às trilhas interpretativas a Estação Ecológica de Avaré dispõe de algumas trilhas, contudo não estão estruturadas com o objetivo de interpretação da natureza. Uma trilha é considerada interpretativa quando seus recursos são traduzidos para o visitante através de guias especializados, folhetos ou painéis (Vasconcellos, 2006). Estas são consideradas um importante instrumento para o desenvolvimento do Subprograma de Educação Ambiental, auxiliando na assimilação do conhecimento sobre as relações que ocorrem na natureza e sensibilizando os visitantes acerca da importância das áreas e recursos naturais (Toledo e Pelicioni, 2005).

É proposta a implantação de uma Trilha de Interpretação denominada Trilha Memória da Ferrovia, com início próximo à casa antiga da estrada de ferro em direção à ponte também antiga, a qual representa um importante atrativo de cunho histórico-cultural edificado. Pontos interpretativos podem ser escolhidos de acordo com as características ambientais, relações ecológicas, sequências de fenômenos, atrativos do percurso, importância das espécies, entre outros (Souza e Tabanez, 2012).

Foi realizada entrevista junto à Secretária de Educação Municipal. Esta desconhecia a existência da Estação Ecológica de Avaré. Afirmou ser favorável ao desenvolvimento de projetos e atividades de educação ambiental com alunos da rede de ensino.

A Secretária informou também que nas escolas municipais foi implementado um projeto de coleta seletiva de resíduos sólidos, realizado há três anos, com a participação de alunos. Há duas escolas localizadas próximo à E.Ec. Avaré, a EMEB Norma Lélia e EMEB Duilio Gambini e, que na abrangência do município existem por volta de 9.140 alunos, considerando-se as escolas municipais, as estaduais e as particulares (Apêndice B).

Foi salientada a importância de serem desenvolvidos cursos de formação em Educação Ambiental para os professores das escolas. Espaços não formais como as Unidades de Conservação podem contribuir nos processos de capacitação de professores (Tabanez, 2007). 
É importante que seja elaborado um projeto de educação ambiental específico para os alunos das escolas localizadas na zona de entorno de $20 / 30 \mathrm{~km}$, em consonância com a Secretaria Municipal de Educação. Nesse projeto, os educandos poderão realizar atividades diversas na Estação Ecológica mediante prévio agendamento. Deve seguir as Diretrizes para Estratégia Nacional de Comunicação e Educação Ambiental em Unidades de Conservação - ENCEA (Brasil, 2009).

Foi realizada entrevista com o gestor da Unidade, que explicou ser importante priorizar o atendimento a alunos de nível superior de ciências biológicas, escolas técnicas e também o recebimento de alunos do nível básico.

O número e o perfil dos visitantes são importantes para o planejamento das atividades de educação ambiental (Herculiani et al., 2009). Informações obtidas junto à E.Ec. Avaré revelaram que esta é visitada pelos moradores do município, os quais têm preferência por uma trilha próxima ao cerradão, a qual não se encontra estruturada para o desenvolvimento de atividades de interpretação da natureza. Essa é uma trilha que poderia ser utilizada para atividades de educação ambiental. É importante que sejam realizadas atividades com esse público, com o objetivo de sensibilizá-lo quanto à importância dessa Unidade de Conservação para o município e região.

$\mathrm{O}$ gestor desta Estação Ecológica salientou também que a população do entorno procura o local em busca de madeira e sapé e que desconhecem a finalidade nobre da mesma. De acordo com Herculiani et al. (2009), trabalhos de educação ambiental são estratégias de grande importância para integrar as comunidades de entorno no processo de conhecimento da importância de proteção dos patrimônios natural e histórico-cultural abrigados pela UC.

$\mathrm{Na}$ zona de entorno da E.Ec. Avaré são desenvolvidas atividades econômicas como plantio de laranja, eucalipto, cana de açúcar e pastoreio, segundo o gestor da área. Existe parceria junto aos usineiros de cana-de-açúcar no combate ao fogo. Estes estão cientes sobre questões relacionadas à necessidade de recomposição florestal e formação de corredores ecológicos.

Há também na Unidade uma capela denominada "Bom Jesus" (Figura 5), onde ocorrem reuniões frequentes e atividades festivas, como a de louvor ao Senhor Bom Jesus, que atrai inúmeros devotos, conforme informações obtidas junto ao gestor. Dado o alto caráter religioso local, foi sugerida a possibilidade de implantação de um Centro de Tradições Caipira e Religioso. Poder-se-iam elaborar trabalhos de educação ambiental explorando essas tradições apontadas acima.

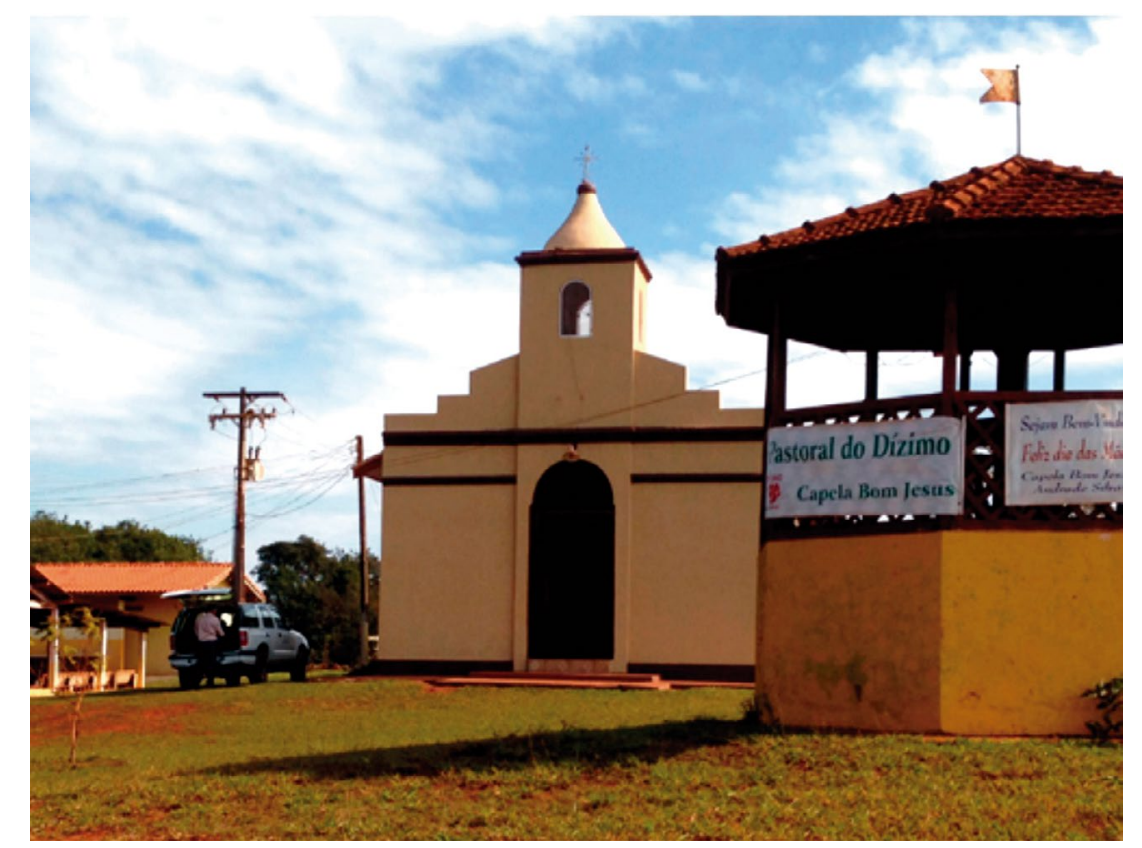

Figura 5. Capela "Bom Jesus" no interior da Estação Ecológica.

Figure 5. Chapel in the Ecological Station. 
Observou-se que há uma estrada que atravessa a Unidade de Conservação. Foi obtida junto à Unidade, a informação de que muitos indivíduos, grupos e casais motorizados deixam esta estrada e adentram alguns caminhos, antigos aceiros. Propõe-se o desenvolvimento de trabalhos que visem conscientizar esse público quanto às normas existentes relacionadas ao uso de uma Estação Ecológica.

Ainda, é importante salientar a necessidade de impedir o tráfego de veículos de grande porte, os quais utilizam essa estrada para atravessar a UC e causam impactos negativos aos meios biótico, físico e antrópico (Figura 6). Torna-se contraditório, desse modo, o trabalho de sensibilização do público em relação a importância desta Estação Ecológica como área de proteção dos recursos naturais, se nada for feito para evitar o impacto do tráfego desses veículos dentro desta área protegida.

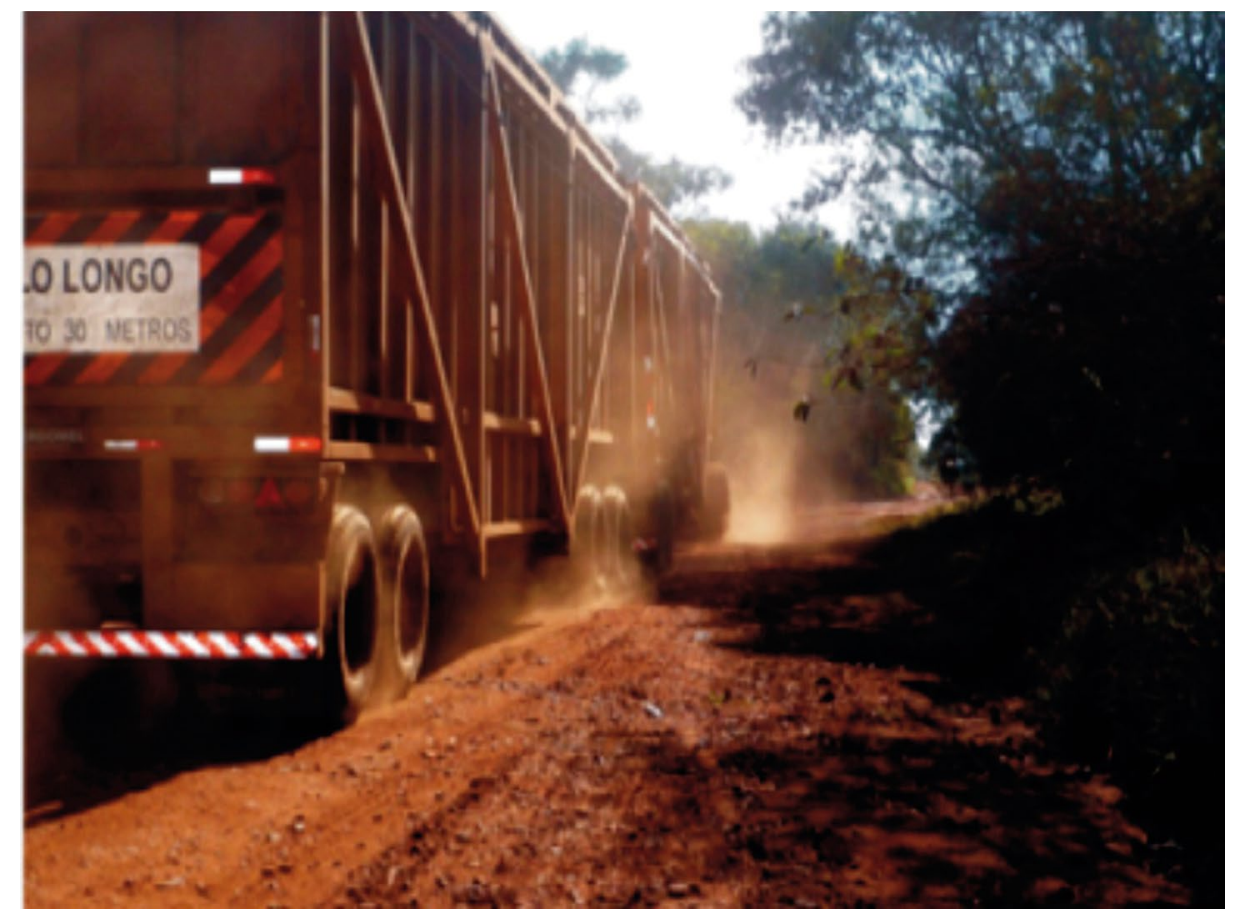

Figura 6. Treminhão atravessando a Unidade de Conservação.

Figure 6. Truck crossing the protected area.

\section{CONCLUSÕES}

A pesquisa revelou que a E.Ec. Avaré é uma área muito importante para a região, no tocante ao desenvolvimento de atividades de educação ambiental, porém, até o presente, não dispõe de infraestrutura física para o desenvolvimento destas atividades, carece de trilhas interpretativas e, desde sua criação não tem um Subprograma de Educação Ambiental implantado, faltando, inclusive, recursos humanos para o desenvolvimento destas atividades. Salienta-se a importância de serem ministrados cursos de formação em Educação Ambiental para os professores das escolas da região, com o objetivo de habilitá-los para o desenvolvimento das atividades de educação ambiental nesta unidade.

\section{AGRADECIMENTOS}

Ao pesquisador científico Léo Zimback, gestor da Estação Ecológica de Avaré, e à Dra. Lucia Helena Lelis, Secretária Municipal de Educação de Avaré, pelas informações prestadas, e à pesquisadora Marina Mitsue Kanashiro, pela confecção da Figura 1. 


\section{REFERÊNCIAS BIBLIOGRÁFICAS}

AGENDA 21. 1992. Disponível em: <http://www.mma.gov.br/responsabilidade-socioambiental/agenda-21>. Acesso em: 10 nov. 2015.

ARZOLLA, F.A.R.D.P. et al. A criação da Estação Ecológica de Avaré, SP: adequação do Horto Florestal Andrada e Silva ao Sistema Nacional de Unidades de Conservação. In: CONGRESSO BRASILEIRO DE UNIDADES DE CONSERVAÇÃO, 7., 2012, Natal. Anais.... Disponível em: $<$ http://www.icongresso.itarget.com.br/useradm/ anais/?clt>. Acesso em: 27 jul. 2014.

ASSOCIAÇÃO BRASILEIRA DE NORMAS TÉCNICAS - ABNT. NBR 9050: acessibilidade a edificações, mobiliário, espaços e equipamentos urbanos. Disponível em: <http://pfdc.pgr.mpf.mp.br/ atuacao-e-conteudos-de-apoio/legislacao/pessoa-deficiencia/norma-abnt-NBR-9050/view>. Acesso em: 20 mar. 2015.

BRASIL. Constituição da República Federativa do Brasil de 1988. Disponível em: < http://www.planalto. gov.br/ccivil_03/constituicao/constituicao.htm>. Acesso em: 14 abr. 2015.

. Lei $\mathrm{n}^{\circ}$ 6.902, de 27 de abril de 1991. Dispõe sobre a criação de Estações Ecológicas, Áreas de Proteção Ambiental e dá outras providências. Disponível em: <http://www.planalto.gov.br/ ccivil_03/ leis/16902.htm>. Acesso em: 30 jul. 2014.

. Lei no 9.795, de 27 de abril de 1999. Dispõe sobre a Educação Ambiental, institui a Política Nacional de Educação Ambiental e dá outras providências. Disponível em: <http:www.mma.gov.br $>$. Acesso em: 27 jul. 2014.

. Ministério do Meio Ambiente. Sistema Nacional de Unidades de Conservação da Natureza SNUC - Lei n ${ }^{\circ}$ 9.985, de 18 de julho de 2000. Brasília, DF, 2000. 32 p.

. Ministério do Meio Ambiente - MMA; Instituto Chico Mendes de Conservação da Biodiversidade ICMBio. Estratégia Nacional de Comunicação e Educação Ambiental no âmbito do Sistema Nacional de Unidades de Conservação - ENCEA. Brasília, DF: MMA, dez. 2009. 27 p.

CARTA da Terra. 2000. Disponível em: <http://www.mma.gov.br/responsabilidade-socioambiental/ agenda-21/carta-da-terra $>$. Acesso em: 15 out. 2015.

CONFERÊNCIA RIO-92/ECO-92. 1992. Disponível em: <http://www.senado.gov.br/noticias/Jornal/em discussao/rio20/a-rio20/conferencia-rio-92-sobre-o-meio-ambiente>. Acesso em: 15 abr. 2015.

CONFERÊNCIA de Tbilisi. 1977. Disponível em: <http://www.ambiente.sp.gov.br/wp-content/uploads/cea/ Tbilisicompleto.pdf.> Acesso em: 14 abr. 2015.

DECLARAÇÃO de Estocolmo. 1972: declaração de Estocolmo sobre o ambiente humano. Disponível em: <http://www.direitoshumanos.usp.br/index.php/Meio-Ambiente/declaracao-de-estocolmosobre-o-ambiente-humano.html>. Acesso em: 14 abr. 2015.

ENCONTRO de Belgrado - 1975. Disponível em: <http://www.portal.mec.gov.br/secad/arquivos/pdf/ educacaoambiental/historia.pdf $>$. Acesso em: 14 abr. 2015.

HERCULIANI, S. et al. Análise das atividades de educação ambiental realizadas no Parque Estadual Alberto Löfgren. Rev. Inst. Flor., v. 21, n. 2, p. 227-242, dez. 2009. 
HERCULIANI, S. et al. Educação ambiental na Estação Ecológica de Avaré.

HUXLEY, T.H. Evidence as to man's place in nature. [S. 1.]: Courier Corporation, 2013. 192 p.

LÜDKE, M.; ANDRÉ, A.D.E.M. Pesquisa em educação: abordagens qualitativas. São Paulo: EPU, 1986. 100 p.

MARCONDES, M.A.P. et al. Terminologia em manejo de unidades de conservação. IF Sér. Reg., n. 34, p. 1-63, 2008.

OLIVEIRA, J.B. et. al. Mapa pedológico do Estado de São Paulo. Campinas: IAC/EMBRAPA, 1999.

SÃO PAULO (Estado). Decreto $\mathrm{n}^{\circ} 51.453$, de 29 de dezembro de 2006. Cria o Sistema Estadual de Florestas - SIEFLOR e dá providências correlatas. Disponível em: $<$ http://www.governo-sp.jusbrasil.com.br/ legislacao/92176/decreto-51453-06>. Acesso em: 12 mar. 2015.

Lei $\mathrm{n}^{0}$ 12.780, de 30 de novembro de 2007. Institui a Política Estadual de Educação Ambiental. Disponível em: <http://www.al.sp.gov.br/norma/?id=74690>. Acesso em: 14 mar. 2015.

Secretaria do Meio Ambiente. Resolução SMA n 59 de 27 de agosto de 2008. Regulamenta os procedimentos administrativos de gestão e fiscalização do uso público nas Unidades de Conservação de proteção integral do Sistema Estadual de Florestas do Estado de São Paulo, e dá outras providências. Disponível em <http://www.ambiente.sp.gov.br/legislacao/resolucoes-sma/resolucao-sma-59-2008>. Acesso em: 10 abr. 2015.

Decreto $n^{0}$ 56.616, de 28 de dezembro de 2010. Cria a Estação Ecológica de Avaré na área que compõe o Horto Florestal de Andrada e Silva, Município de Avaré, em terras que estão sob posse e domínio da Fazenda Pública do Estado de São Paulo, e dá providências correlatas. Disponível em: <http://www.al.sp.gov.br/ repositorio/legislacao/decreto/2010/decreto-56616-28.12.2010.html>. Acesso em: 17 mar. 2015.

SENTELHAS, P.C. et al. Balanços hídricos climatológicos de 500 localidades brasileiras do Brasil. 1999. Disponível em: <http:// www. lce.esalq.usp.br/nurma.html.>. Acesso em: 9 dez. 2015.

SOUZA, S.A.; TABANEZ, M.F. Roteiro interpretativo da Trilha das Árvores Gigantes: subsídio ao Programa de Uso Público do Parque Estadual de Porto Ferreira, Porto Ferreira - SP. IF Sér. Reg., n. 49, p. 1-56, 2012.

TABANEZ, M. F. Aprendizagem profissional da docência: repercussões de um projeto de políticas públicas em Educação Ambiental. 2007. 299 f. Tese (Doutorado em Educação) - Centro de Educação e Ciências Humanas, Universidade Federal de São Carlos, São Carlos.

TOLEDO, R.F.; PELICIONI, M.C.F. Educação ambiental em unidades de conservação. In: PHILIPPI Jr., A.; PELICIONI, M.C.F. (Ed.). Educação ambiental e sustentabilidade. Barueri: Manole, 2005. p. 749-769. (Coleção Ambiental, 3).

TRATADO de educação ambiental para sociedades sustentáveis e responsabilidade global. 1992. Disponível em: <http://www.meioambiente.pr.gov.br/arquivos/ File/coea/Tratado_Educacao_ Ambiental. pdf $>$. Acesso em: 10 out. 2015

VASCONCELLOS, J.M. de O. Educação e interpretação ambiental em Unidades de Conservação. Curitiba: Fundação O Boticário de Proteção à Natureza, 2006. 86 p. (Cadernos de Conservação, n. 4). 
Apêndice A. Questionário

Appendix A. Questionnaire

\section{ENTREVISTA COM A SECRETÁRIA DE EDUCAÇÃO}

Data $1+1$

Nome:

Cargo:

1- São desenvolvidas atividades de Educação Ambiental do Município?

2- São desenvolvidos projetos de Educação Ambiental de maneira sistemática junto aos alunos?

3- Há interesse dos professores participarem de cursos que poderiam ser ministrados por técnicos do Instituto Florestal?

\section{ENTREVISTA COM GESTOR DA UNIDADE DE CONSERVAÇÃO}

Data_ _ _ _ _ _ _ _

Nome:

Cargo:

A- Estruturas físicas:

1- A Unidade de Conservação - UC dispõe de estruturas físicas relacionadas à visitação e à educação ambiental?

Se sim, quais e, se não, tem planejamento de implantar?

B- Monitoria:

1- A Unidade conta com funcionários? Especificar quantidade, cargos, escolaridade, atividade executada, etc.

2- Qual o número de monitores na UC?

3- Quais as características exigidas? (Formação acadêmica, curso, ano, habilidades, etc.).

4- Os monitores são estagiários ou são contratados? Qual é a duração do estágio?

5- Qual o tempo do contrato dos monitores no programa de uso público?

6- Há rotatividade dos monitores? Estima quanto? Quais são as causas?

7- Há treinamento para os monitores? Como é realizada a formação? Qual conteúdo, técnicas? Quem dá o treinamento?

8- Há avaliação das atividades por eles desenvolvidas? Periodicidade.

9- Tem programa de estágio para cada estagiário?

10 - Se for um curso pode disponibilizar o programa? Tem apostilas ou outro material didático? Quem ministra o curso?

C- Educação Ambiental:

1- O que o gestor da UC entende por Educação Ambiental - EA?

2- São realizadas atividades de educação ambiental na UC? Quais? Qual a frequência?

3- Qual é o público-alvo?

4- Quem planeja as atividades?

5- São realizadas atividades com os professores das escolas? Cursos, palestras, etc.?

6- Tem os programas? Pode disponibilizar? Qual a frequência da realização das atividades?

7- São oferecidos cursos para alunos? Tem o programa? Pode disponibilizar?

8- Realiza atividades de EA com as comunidades de entorno? Quais atividades são realizadas? Tem o programa?

Pode disponibilizar?

9- São realizados eventos comemorativos? Quais?

10- A população do entorno traz demandas para a Estação Ecológica? Quais? São atendidas?

11- A Estação Ecológica tem Conselho Consultivo constituído? Os membros do sistema de ensino participam das atividades exercidas? 
HERCULIANI, S. et al. Educação ambiental na Estação Ecológica de Avaré.

D- Visitação:

1- Há visitação? É controlada? Os visitantes pagam ingresso de entrada?

2- Há áreas preferenciais de visitação?

3- Qual o período de maior frequência de visitantes? De onde vêm esses visitantes?

4- Qual é o perfil/interesse dos visitantes?

5- Quais são as atividades de recreação e lazer desenvolvidas? As atividades promovem o conhecimento do meio ambiente?

6- São desenvolvidos serviços que transmitem ao visitante conhecimentos e valores do patrimônio natural e cultural da área? Se sim, quais? Há fôlderes, panfletos, placas explicativas, etc.?

E- Unidade de Conservação e seu entorno:

1- Há ONGs atuando junto a Unidade e/ou no entorno?

2- Como a comunidade local se relaciona com a Unidade? Interna e externa à Área?

3- Quais atividades econômicas são desenvolvidas nas proximidades? Há problemas ambientais decorrentes dessas atividades? Quais?

4- Há inter-relação da Unidade com a população da área de influência? Explique.

5- São desenvolvidos programas de caráter educativo na Unidade e nas comunidades vizinhas? Quais? Esses programas visam uma maior integração e envolvimento da comunidade com a Unidade?

6- Há parcerias com órgãos públicos? E com a iniciativa privada? Se sim, quais?

F- Conflitos:

1- A Unidade enfrenta conflitos de alguma natureza? Se sim, quais? Você identifica as estratégias para solucionar e/ou minimizar?

2- Há parcerias? Prefeitura? Empresas? 


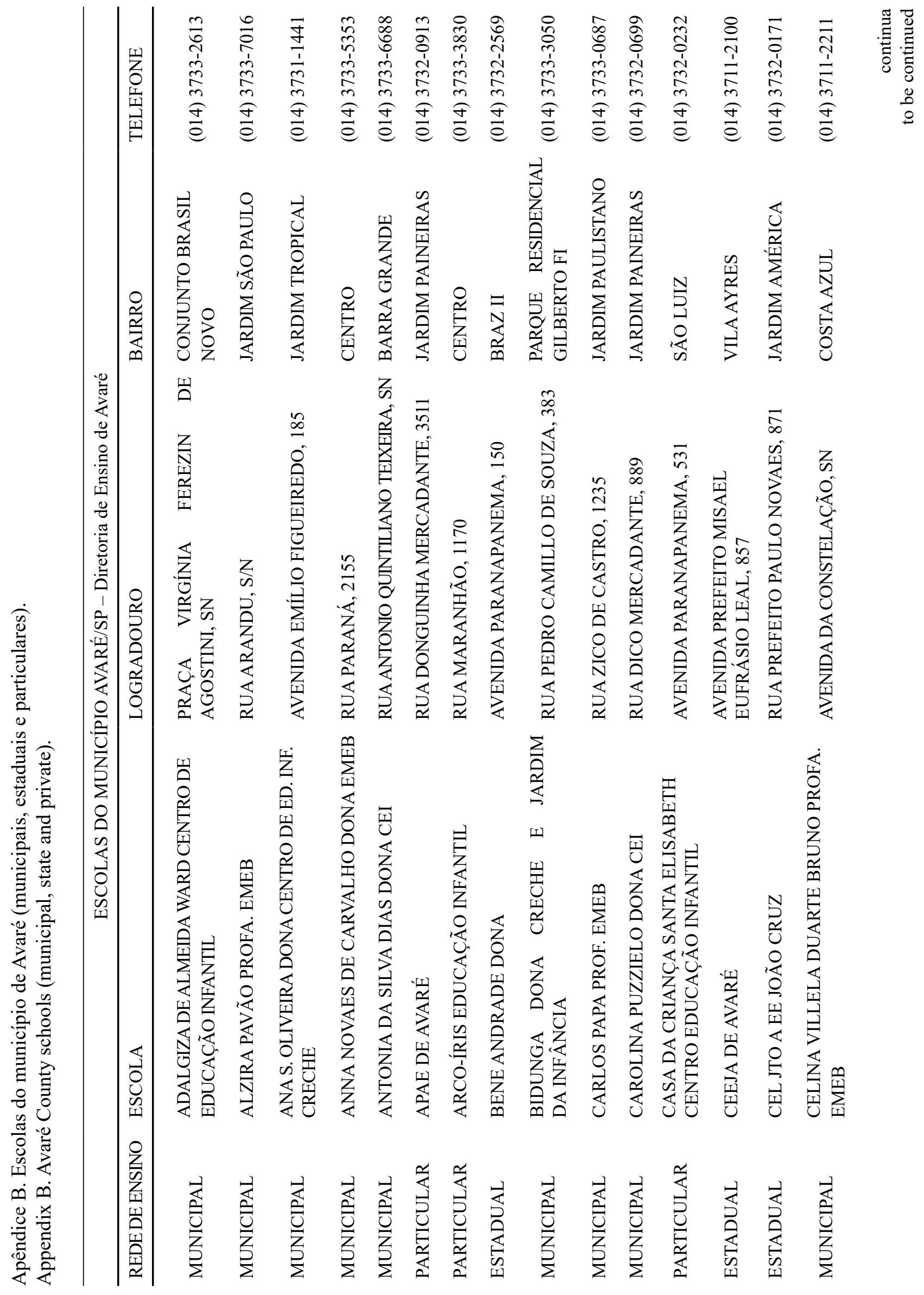


HERCULIANI, S. et al. Educação ambiental na Estação Ecológica de Avaré.

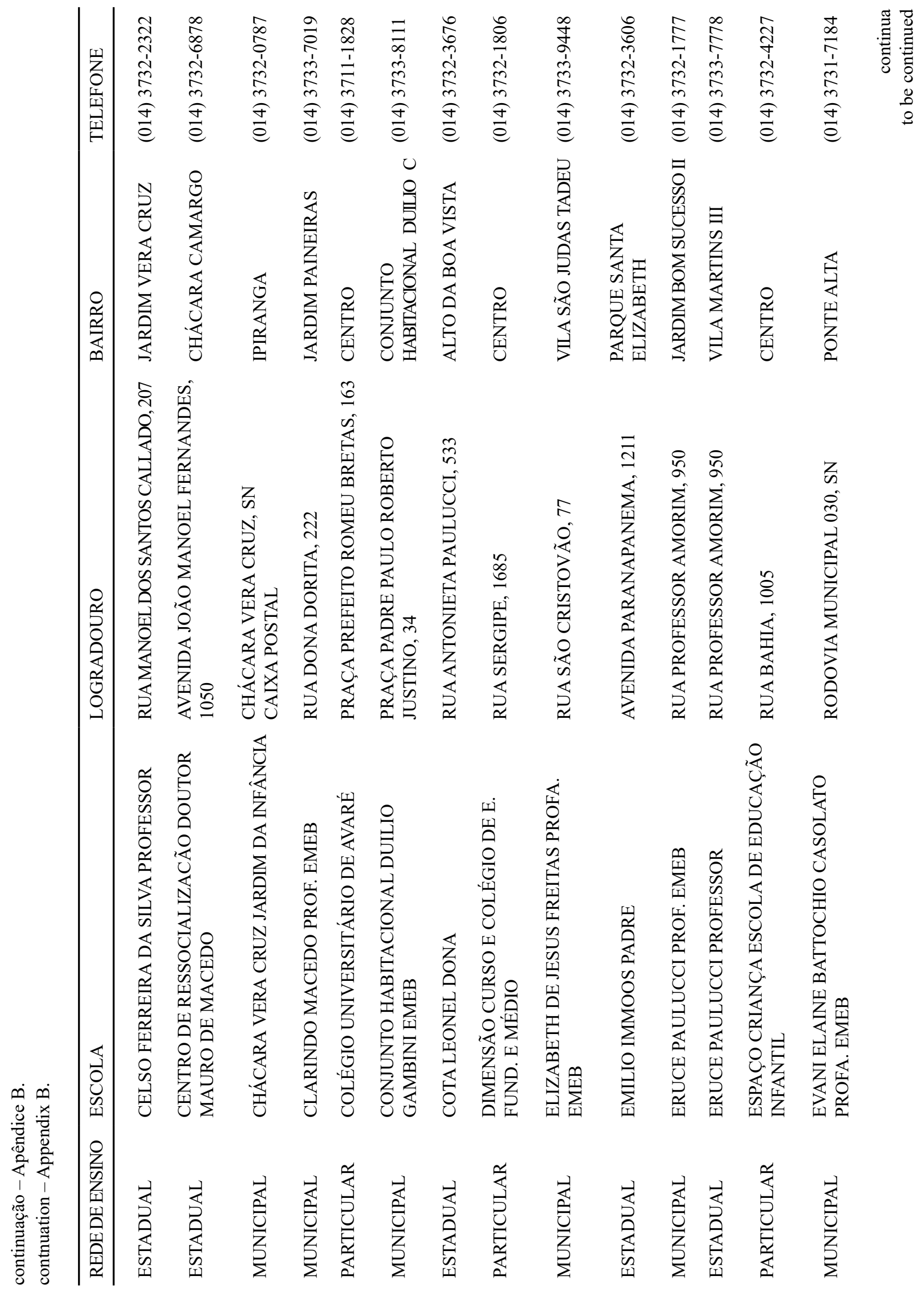




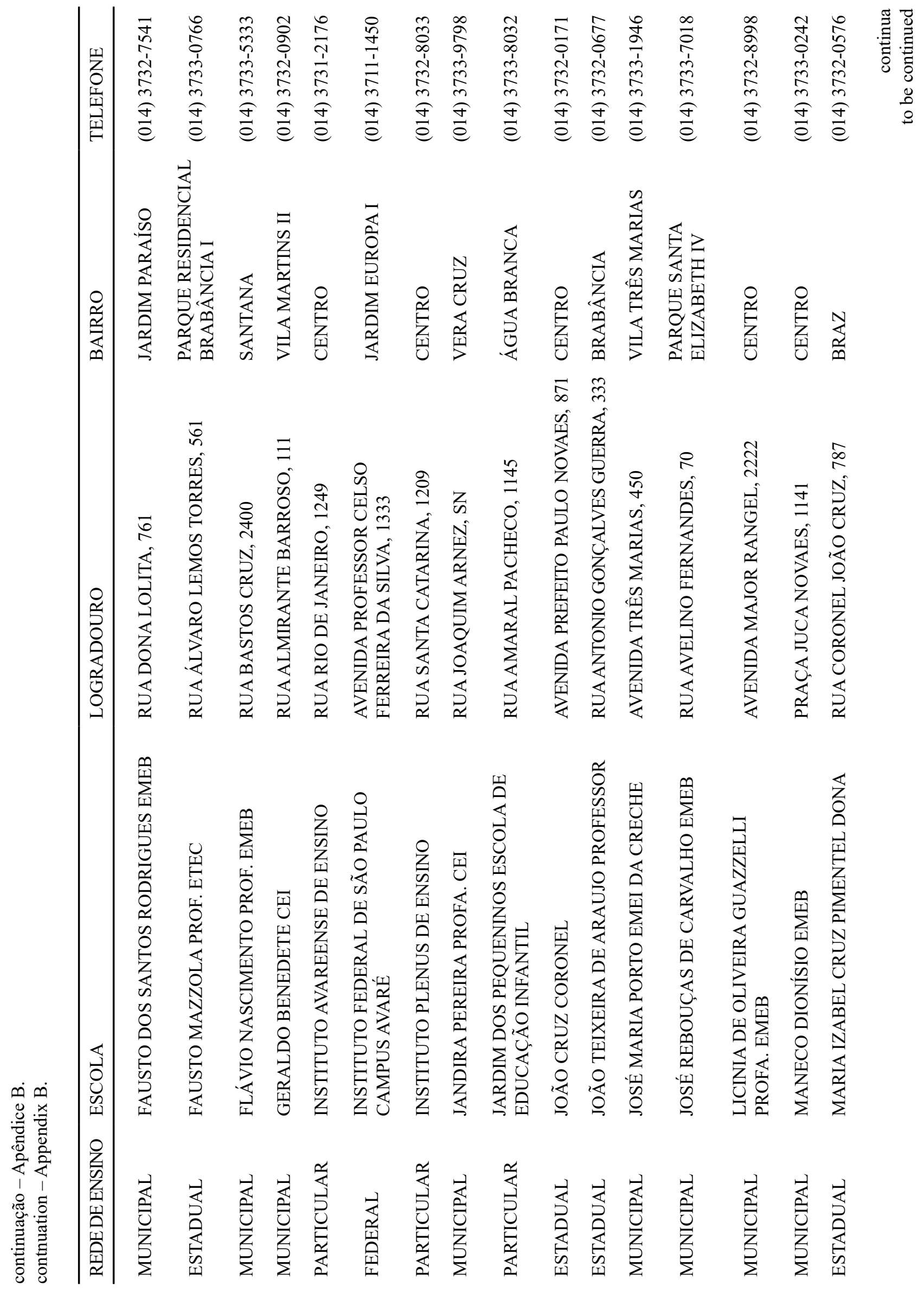


HERCULIANI, S. et al. Educação ambiental na Estação Ecológica de Avaré.

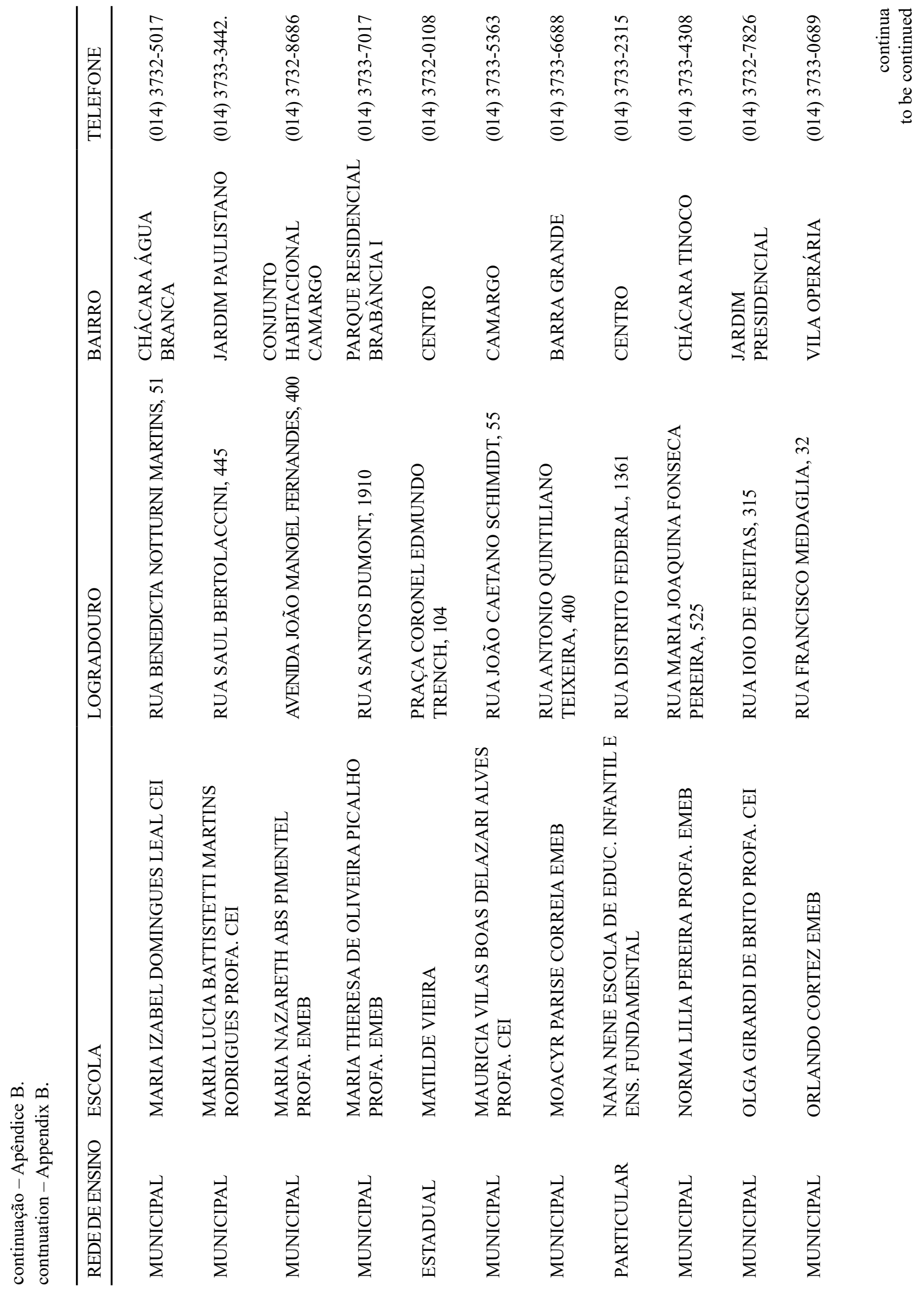




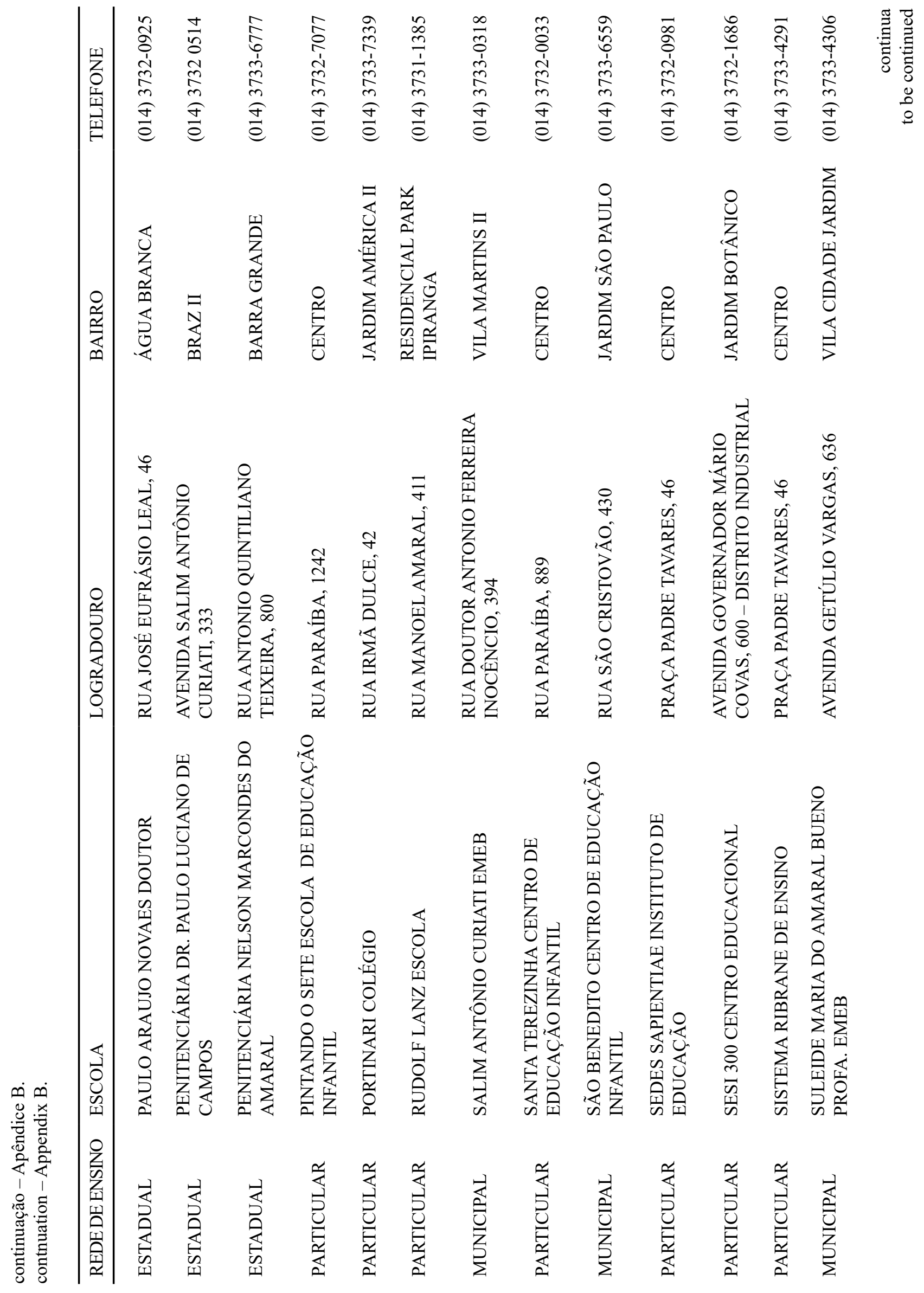


HERCULIANI, S. et al. Educação ambiental na Estação Ecológica de Avaré.

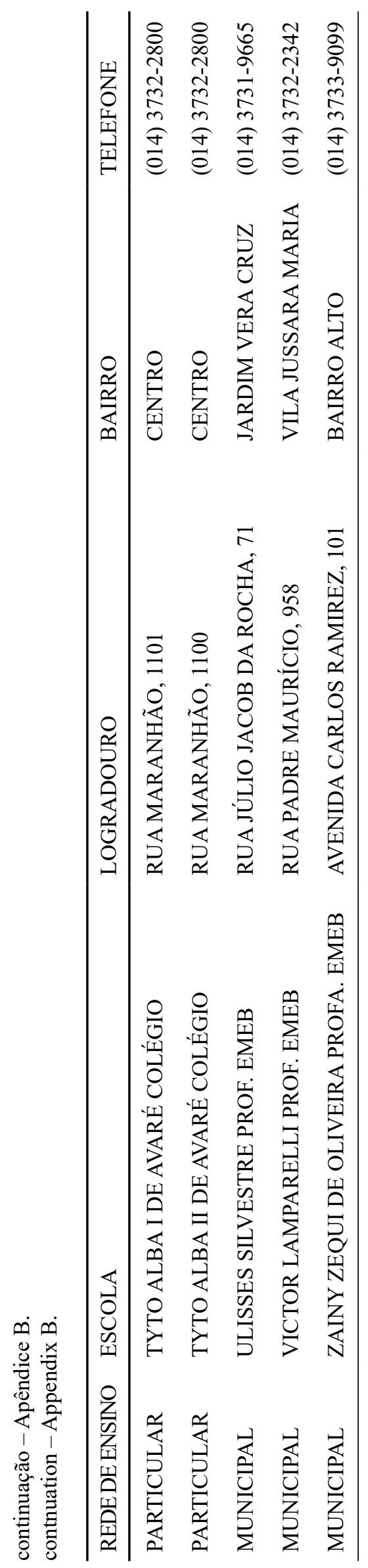

IF Sér. Reg. n. 54 p. 5-23 maio 2016 